\title{
PENERAPAN PEMBELAJARAN BERORIENTASI CHEMOENTREPRENEURSHIP (CEP) TERHADAP KREATIVITAS SISWA SMA MODERN PONDOK SELAMAT PADA MATERI KELARUTAN DAN KsP
}

\author{
Teguh Wibowo' dan Ariyatun ${ }^{2}$ \\ ${ }^{1}$ Pendidikan Kimia, Fakultas Sains dan Teknologi, \\ Universitas Islam Negeri Walisongo \\ 2Program Studi Pendidikan Kimia Pascasarjana, Universitas Negeri Semarang \\ *E-mail: teguhwibowo@walisongo.ac.id
}

\begin{abstract}
ABSTRAK
Penelitian ini bertujuan untuk mengetahui peningkatan kreativitas siswa setelah mendapatkan penerapan pembelajaran kimia berorientasi chemoentrepreneurship (CEP). Penelitian ini menggunakan metode preexperimental design melalui one group pre-test - post-test design. Subjek penelitian ini adalah siswa kelas XIIPA SMA Modern Pondok Selamat Kendal, pada materi kelarutan dan $K_{\text {sp. }}$. Adapun teknik pengambilan sampel dilakukan secara purposive sampling. Teknik pengumpulan data berupa observasi untuk mengetahui kreativitas siswa. Teknik analisis data dilakukan secara analisis deskriptif dan statistik inferensial (paired sample $t$-test dan uji $\mathrm{N}$-gain). Berdasarkan hasil penelitian tersebut dapat dilihat bahwa pembelajaran kimia berorientasi CEP dapat meningkatkan kreativitas siswa dalam pembelajaran. Rerata skor kreativitas siswa pada post-test lebih baik daripada pre-test yaitu dengan nilai 41,5 dan 27,8 serta thitung sebesar -27,738 dan tabel sebesar 2,034 (thitung $<$ tabel $=-27,738<-2,034$ ) dan nilai $N$-gain $=0,62$.
\end{abstract}

Kata kunci: chemoentrepreneurship (CEP), kreativitas, kelarutan, $\mathrm{K}_{\mathrm{sp}}$.

\begin{abstract}
This study aimed to determine the increased creativity of students after getting the endeavor of chemoentrepreneurship (CEP)-oriented chemistry learning. This study used pre-experimental design methods by one group pre-test - post-test design. The subject in this study were class $X$ students of Pondok Modern Selamat of high school in Kendal on the solubility and $K_{s p}$ material. Techniques of data collection are the assessment sheat observation to know creativity of student. The technique to analysis data is descriptive and inferential statistical analysis (paired sample t-test and $\mathrm{N}$-gain). The results showed that there the chemistry teaching of CEP oriented can increase creativity of students on teaching. The mean score of students' creativity on post-test was better than the pre-test, each with a value of 41.5 and $27.8, t_{\text {count }}-27,738$ and $t_{\text {table }} 2,034$ ( $t_{\text {count }}$ $\left.<t_{\text {table }}=-27,738<-2,034\right)$ and $N$-gain $=0,62$.
\end{abstract}

Keywords: chemoentrepreneurship (CEP), creativity, solubility, $K_{s p}$.

DOI: https://doi.org/10.15575/jtk.v3i1.2030 


\section{T. Wibowo \& Ariyatun}

\section{PENDAHULUAN}

Ilmu kimia merupakan salah satu cabang ilmu sains yang mengkaji tentang struktur materi dan perubahan-perubahan yang dialami materi dalam proses alamiah maupun eksperimen yang disusun (Keenan et al., 2001). Ilmu kimia sebagai kajian berupa proses dan produk, yang semestinya mampu memberikan kontribusi yang cukup signifikan dalam meningkatkan kecerdasan siswa. Belajar kimia dapat diartikan sebagai upaya untuk mengetahui berbagai gejala alam agar mendapatkan suatu hasil yang bermanfaat bagi kesejahteraan manusia. Oleh karena itu, pada pembelajaran kimia dapat dihubungkan langsung dengan berbagai objek atau fenomena yang bermanfaat di sekitar kehidupan manusia (Supartono, 2006).

Ilmu kimia cenderung kurang disenangi dan dipandang sulit oleh siswa. Hal ini dikarenakan proses pembelajarannya yang terlalu monoton pada ceramah di kelas dan kurang menerapkan proses pembelajaran yang bermakna (Rahmawanna dkk., 2016). Pada kejadian ini kadang-kadang membuat konsentrasi siswa menjadi mudah terpecah dengan hal lain, sehingga sebagian besar siswa tidak dapat memahami dan menyerap materi kimia yang disampaikan guru dengan baik. Akibatnya hal ini akan berdampak langsung pada nilai pengukuran pemahaman siswa. Hal itu diduga karena selama ini proses pembelajaran cenderung berpusat pada guru dan kurang memperhatikan kreativitas siswa (Khan et al., 2012).

Materi kelarutan dan hasil kelarutan merupakan bagian dari materi kimia yang memerlukan penerapan matematis atau perhitungan kimia yang cukup kompleks sehingga untuk menyelesaikannya siswa dituntut untuk dapat berpikir kreatif. Oleh karena itu, materi kelarutan dan hasil kelarutan ini merupakan salah satu materi yang sering menimbulkan kesulitan bagi siswa dalam mempelajarinya (Pratiwi, dkk., 2015).
Penerapan Pembelajaran Berorientasi Chemoentrepreneurship (CEP) terhadap Kreativitas Siswa SMA Modern Pondok Selamat pada Materi Kelarutan dan $K_{s p}$

Berdasarkan hasil wawancara terhadap guru dan siswa SMA Modern Pondok Selamat, siswa mengalami kesulitan pada materi kelarutan dan hasil kali kelarutan. Kemampuan matematika yang dimiliki siswa masih tergolong rendah, sehingga kreativitas dalam menyelesaikan soal pun masih rendah. Siswa hanya memperhatikan materi yang diberikan oleh guru saja. Selain itu, guru dalam pembelajaran kurang dapat menerapkan strategi yang bervariasi sehingga kreativitas siswa terabaikan.

Kreativitas memiliki tiga ranah kemampuan, yaitu (1) kemampuan membuat kombinasi atau susunan baru, (2) kemampuan berdasarkan informasi yang tersedia, dan (3) kemampuan secara operasional mencerminkan kelancaran, keluwesan dan orisinalitas kemampuan berpikir (Munandar, 2009). Kreativitas dibutuhkan untuk mempelajari materi kelarutan dan hasil kali kelarutan, salah satunya berguna untuk pemahaman konsep kelarutan dimana kelancaran berpikir membantu siswa untuk memahami kelarutan dan pengendapan zat. Serta keluwesan dan orisinalitas siswa diharapkan mampu memunculkan ide-ide tentang cara menemukan solusi untuk memecahkan masalah yang diberikan (Damayanti dkk., 2014).

Kurangnya perhatian pada kreativitas siswa ini didukung oleh hasil observasi yang dilakukan Supartono dkk. (2009b) di SMA Negeri 1 Jepara yang menunjukkan bahwa dalam pembelajaran di kelas siswa cenderung pasif, materi di kelas belum sepenuhnya dikaitkan dengan fenomena dalam kehidupan sehari-hari, serta siswa belum dibekali dengan keterampilan berwirausaha.

Menurut Starcher dalam Supartono (2006), entrepreneurship berarti seseorang yang melakukan atau mengusahakan suatu proyek atau aktivitas secara signifikan. Sehingga entrepreneurship dapat diartikan sebagai inovasi dalam penciptaan nilai-nilai baik segi ekonomi, sosial dan lain-lain. 
Sikap kewirausahaan merupakan kecenderungan bertindak, perasaan/emosi, serta pola pikir, pandangan pendapat atau opini seseorang terhadap objek sikap tertentu yang berkaitan dengan kewirausahaan (Surachman, 2011). Kewirausahaan tidak selalu identik dengan watak atau ciri pengusaha semata, dikarenakan watak atau ciri ini dimiliki juga oleh seseorang yang bukan pengusaha (Hendro, 2011). Sikap dalam hal berwirausaha sebenarnya ada pada setiap pribadi manusia yang memiliki perilaku inovatif, kreatif, menyukai perubahan, pembaharuan, kemajuan dan tantangan.

Untuk menjadi wirausahawan, seseorang harus memilki indikator kewirausahaan. Menurut Alma (2007) indikator seorang wirausahawan dapat diuraikan sebagai berikut.

1) Percaya diri, dimulai dari pribadi yang optimis, tidak mudah terpengaruh dengan pendapat dan saran dari orang lain. Karakteristik kematangan seseorang adalah tidak tergantung pada orang lain, memiliki rasa tanggung jawab yang tinggi, objektif dan kritis, emosional sudah stabil, tingkat sosialnya tinggi.

2) Berorientasi pada tugas dan hasil., seseorang yang selalu mengutamakan tugas dan hasil adalah orang yang selalu mengutamakan prestasi, berorientasi pada laba, ketekunan dan kerja keras, mempunyai dorongan kuat, dan berinisiatif. Berinisiatif artinya selalu ingin mencari dan memulai sesuatu. Untuk memulai diperlukan adanya niat dan tekad yang kuat sehingga usahanya akan semakin maju dan berkembang.

3) Pengambilan resiko, seorang wirausahawan sering dikatakan selalu menyenangi tantangan. Ciri ini dibawa dalam wirausaha yang juga penuh dengan resiko dan tantangan seperti persaingan, harga tidak naik, barang tidak laku dan lain sebagainya. Namun, semua tantangan ini harus dihadapi dengan penuh perhitungan.
4) Kepemimpinan, seorang wirausaha yang berhasil yang selalu memiliki sifat kepemimpinan dan keteladanan. orang yang selalu ingin tampil berbeda, menjadi yang pertama dan lebih menonjol. Dengan menggunakan kemampuan kreativitas dan inovasi, seorang wirausahawan selalu menampilkan barang dan jasa-jasa yang di hasilkannya dengan lebih cepat, lebih dulu, dan segera berada di pasar.

5) Keorisinilan, sifat orisinil tentu tidak selalu ada pada diri seseorang. Sikap orisinil ialah tidak hanya bergantung pada orang lain, tetapi memilki pendapat sendiri, ada ide yang orisinil, ada kemampuan untuk melaksanakan sesuatu. orisinil tidak berarti baru sama sekali, tetapi produk mencerminkan hasil kombinasi baru atau reintegrasi dari komponen-komponen yang sudah ada sehingga melahirkan sesuatu yang baru.

Dengan belajar kimia berbagai gejala atau fenomena dalam kehidupan sehari-hari dapat dipelajari dan dimengerti. Oleh karena itu, proses belajar kimia dapat dikaitkan langsung dengan berbagai objek yang bermanfaat dalam kehidupan sehari-hari. Hal tersebut tentunya perlu disertai dengan upaya yang terus menerus untuk mencari dan menemukan pendekatan pembelajaran kimia yang unggul, mampu memotivasi siswa untuk belajar dan dapat mengembangkan life skill. Life skill atau (kecakapan hidup) sendiri artinya suatu kecakapan yang selalu diperlukan oleh seseorang termasuk siswa dimanapun ia berada dalam kehidupan bermasyarakat, baik di dalam kehidupannya nanti ia bekerja, tidak bekerja dan apapun profesinya (Kusuma \& Siadi, 2010). Untuk mewujudkan hal itu diperlukan pembelajaran kimia yang menarik serta memupuk daya kreasi dan inovasi siswa, salah satunya melalui pendekatan pembelajaran berorientasi chemoentrepreneurship (CEP).

Perlu adanya solusi agar pendidikan di sekolah terutama kimia dapat menumbuhkan 


\section{T. Wibowo \& Ariyatun}

kreativitas siswa, yaitu menggunakan pembelajaran kontekstual. Salah satu pembelajaran kontekstual dalam pembelajaran kimia adalah chemoentrepreneurship (CEP). Pembelajaran yang berorientasi $C E P$, mengajarkan siswa untuk menghubungkan langsung pada objek nyata atau fenomena yang ada di sekitar kehidupan sehari-hari (Supartono dkk., 2009a). Sehingga pembelajaran berorientasi $C E P$ juga mengajarkan siswa untuk mempelajari proses pengolahan suatu bahan menjadi produk yang bermanfaat, bernilai ekonomi dan memotivasi siswa untuk berwirausaha (Sudharson et al., 2013). Hasil penelitian yang dilakukan Rasheed (2005) menunjukkan bahwa siswa yang menerima pelatihan kewirausahaan memiliki motivasi/ keinginan yang lebih tinggi daripada siswa yang tidak menerima pelatihan kewirausahaan. Sehingga, Rasheed (2005) pun berpendapat bahwa dibutuhkan pendidikan kewirausahaan sejak dini, agar dapat meningkatkan prestasi siswa.

Pembelajaran kimia berorientasi CEP juga memberikan kesempatan kepada siswa untuk dapat berpendapat dan bertindak dalam suatu hal (Paristiowatia et al... 2015). Penerapan pembelajaran kimia berorientasi CEP dapat membuat siswa lebih banyak mengingat konsep atau proses kimia yang dipelajari. Pembelajaran kimia berorientasi CEP ini diharapkan dapat membuat siswa lebih kreatif sehingga dapat menerapkan ilmu pengetahuan yang sudah dipelajari dalam kehidupannya sehari-hari (Supartono dkk., 2009b).

Konsep pendekatan CEP ini dapat meningkatkan semangat berwirausaha siswa, sehingga penggunaan pendekatan CEP pada mata pelajaran kimia akan lebih menyenangkan dan memberi kesempatan siswa untuk mengoptimalkan potensinya agar menghasilkan suatu produk (Murachman, B, dalam Supartono, 2006). Melalui pendekatan CEP ini bukan berarti membentuk siswa menjadi seorang wirusahawan atau pedagang, tetapi pembelajaran dengan pendekatan CEP diharapkan akan menumbuhkan semangat/jiwa kewirausahaan
Penerapan Pembelajaran Berorientasi Chemoentrepreneurship (CEP) terhadap Kreativitas Siswa SMA Modern Pondok Selamat pada Materi Kelarutan dan $K_{s p}$

bagi siswa dalam proses belajar mengajar. Menurut Dabson dalam Sumarni (2009: 3) semangat/jiwa kewirausahaan seseorang tercermin pada berbagai hal misalnya kemampuan, kemandirian (termasuk di dalamnya adalah kegigihan, kerjasama dalam tim, kreativitas dan inovasi). Pendekatan CEP juga tidak hanya berorientasi pada bidang akademik atau vokasional semata, tetapi juga mempraktekannya untuk memecahkan permasalahan dalam kehidupan sehari-hari (Bently dalam Kusuma \& Siadi, 2010).

Pembelajaran kimia berorientasi CEP memiliki indikator-indikator peningkatan kreativitas diantaranya adalah meningkatnya kemampuan mengajukan banyak pertanyaan, melihat masalah dari berbagai sudut pandang, memberikan banyak ide terhadap suatu masalah, mengungkapkan ide dalam penyelesaian masalah, menyatakan pendapat, mencari dan menganalisis data yang diketahui dalam menyelesaikan masalah, daya imajinasi, dan rasa humor (Mursiti dkk., 2008). Pada umumnya orang yang memiliki kreativitas yang tinggi cenderung mencari pengalaman baru dan lebih suka melakukan hal-hal yang tak terduga (Mulyasa, 2004). Orang yang kreativitasnya rendah lebih bersikap sebaliknya, suka hal-hal yang biasa, sedangkan yang kreativitasnya tinggi cenderung terbuka terhadap ide-ide baru.

Penelitian-penelitian terkait dengan penerapan pembelajaran CEP sudah banyak dilakukan, namun kebanyakan untuk meningkatkan prestasi kognitif dan kemampuan life skill siswa. Diantaranya penelitian Rasheed (2005) yaitu mengembangkan karakteristik wirausaha pada pemuda, pengaruh pendidikan dan pengalaman berwirausaha; Rohmadi (2011) yaitu pembelajaran dengan pendekatan CEP yang Bervisi SETS (Sceince, Environment, Technology and Society) guna meningkatkan kualitas pembelajaran; Sumarti et al., (2014b) yaitu pembelajaran berbasis CEP pada materi hidrokarbon dan minyak bumi dalam meningkatkan soft skills dan minat berwirausaha siswa; Nurmasari et al. (2015) yaitu keefektifan pembelajaran berorientasi 


\section{T. Wibowo \& Ariyatun}

CEP pada pemahaman konsep dan kemampuan life skill siswa; Haryati (2014) yaitu peningkatan kreativitas berwirausaha siswa kelas XII Jasa Boga 1 dalam pengolahan limbah bandeng sebagai peluang usaha melalui unit produksi di SMK Negeri 3 Pati; dan Lelono (2015) tentang peningkatan kemampuan CEP siswa melalui penerapan konsep koloid yang berorientasi life skill. Berdasarkan pemaparan tersebut, maka peneliti tertarik untuk melakukan suatu penelitian tentang pengaruh penerapan pembelajaran kimia berorientasi CEP terhadap kreativitas siswa. Melalui penelitian ini diharapkan mampu memberikan solusi untuk meningkatkan kualitas pendidikan di sekolah, terutama memperkokoh peranan kimia bagi kehidupan.

\section{METODE PENELITIAN}

Penelitian ini dilakukan dengan metode preexperimental design melalui one group pretest - post-test design, yaitu rancangan penelitian yang memberikan perlakuan pada kelompok eksperimen tanpa dibandingkan dengan kelompok kontrol (Creswell, 2013).

Hal ini dilakukan karena peneliti mengganggap bahwa ada beberapa faktor lain yang mempengaruhi variabel terikat (kreativitas). Pengaruh perlakuan yang diberikan dapat dilihat dari perbedaan pre-test dan post-test. Penelitian ini dilaksanakan dalam tiga tahap yaitu: (1) pemberian tes awal sebelum pembelajaran dengan menggunakan pendekatan CEP, (2) pelaksanaan pembelajaran dengan pendekatan CEP dan (3) pemberian tes akhir sesudah pembelajaran dengan pendekatan CEP.

Subjek penelitian ini adalah siswa kelas XIIPA SMA Modern Pondok Selamat Kendal yang terdiri atas 34 siswa pada tahun pelajaran 2017/2018, adapun teknik pengambilan sampel dilakukan secara purposive sampling karena peneliti memilih subjek khusus berdasarkan perbedaan kondisi subjek tersebut, yaitu merupakan kelas reguler, sedangkan yang lain kelas khusus.
Penerapan Pembelajaran Berorientasi

Chemoentrepreneurship (CEP) terhadap

Kreativitas Siswa SMA Modern Pondok

Selamat pada Materi Kelarutan dan $K_{s p}$

Instrumen yang digunakan dalam penelitian ini adalah instrumen nontes berupa lembar observasi untuk mengetahui kreativitas siswa terhadap pelajaran kimia sebelum dan sesudah pembelajaran dengan pembelajaran berorientasi $C E P$ yang dilakukan observasi kolaboratif. Pengolahan data dilanjutkan dengan pengujian statistik berupa uji normalitas untuk mengetahui apakah data sebelum dan sesudah pembelajaran berdistribusi normal atau tidak dengan uji Kolmogorov-Smirnov. Kemudian uji hipotesis dilakukan dengan uji Wilcoxon dengan taraf signifikansi 0,05 dan N-gain.

\section{HASIL DAN PEMBAHASAN}

Hasil penelitian ini meliputi data kreativitas siswa yang didapatkan melalui observasi oleh dua orang observer. Kemudian rata-rata skor kreativitas tiap siswa dari dua observer digunakan sebagai sumber data penelitian ini berdasarkan indikator-indikator yang telah ditentukan. Adapun indikator-indikator kreativitas siswa yaitu (1) rasa keingintahuan terhadap sesuatu, (2) inisiatif bertanya, (3) banyak ide terhadap suatu masalah, (4) kebebasan dalam menyampaikan pendapat, (5) penyelesaian masalah berdasarkan pemikiran sendiri, (6) analisis data yang diketahui dalam menyelesaikan masalah, (7) kemampuan melihat masalah dari berbagai sudut pandang, (8) memiliki rasa humor, (9) mempunyai daya imajinasi dan (10) orisinalitas dalam mengungkapkan gagasan dalam menyelesaikan masalah. Indikator indikator tersebut digunakan sebagai pedoman untuk mengamati kreativitas siswa, yang dinilai menggunakan skala Linkert dengan rentang $1-5$. Berdasarkan observasi yang telah dilakukan observer, diperoleh data pada Tabel 1. 


\section{T. Wibowo \& Ariyatun}

Tabel 1. Hasil Observasi Kreativitas Siswa

\begin{tabular}{|l|c|c|}
\hline \multicolumn{1}{|c|}{ Skor } & Pre-test & Post-test \\
\hline Tertinggi & 34 & 45 \\
\hline Terendah & 24 & 37,5 \\
\hline Rerata & 27,8 & 41,5 \\
\hline Kategori & Cukup & Baik \\
\hline
\end{tabular}

Skor kreativitas siswa tersebut kemudian diuji normalitas, sebagai uji prasyarat uji hipotesis Wilcoxon dengan taraf signifikansi 0,05 dan $\mathrm{N}$ gain. Berdasarkan Tabel 2, diketahui bahwa nilai signifikansi sebesar 0,607 lebih besar dari
Penerapan Pembelajaran Berorientasi Chemoentrepreneurship (CEP) terhadap Kreativitas Siswa SMA Modern Pondok Selamat pada Materi Kelarutan dan $K_{s p}$

0,05 , sehingga dapat disimpulkan bahwa data yang kita uji berdistribusi normal. Selanjutnya untuk uji Wilcoxon dengan bantuan SPSS 17, sesuai dengan Tabel 3.

Tabel 2. Hasil Output Uji Normalitas Kolmogorov-Smirnov

\begin{tabular}{|c|c|c|}
\hline \multicolumn{2}{|c|}{$N$} & Unstandardized Residual \\
\cline { 2 - 3 } & Mean & 34 \\
\hline Normal Parametersa & Std. Deviation & .0000000 \\
\cline { 2 - 3 } & Absolute & 2.39574603 \\
\hline \multirow{2}{*}{$\begin{array}{c}\text { Most Extreme } \\
\text { Differences }\end{array}$} & & .131 \\
\cline { 2 - 3 } & Positive & .131 \\
\cline { 2 - 3 } & Negative & -.069 \\
\cline { 2 - 3 } & Kolmogorov-Smirnov Z & .762 \\
\hline \multicolumn{2}{|c|}{ Asymp. Sig. (2-tailed) } & .607 \\
\hline \multicolumn{2}{|c|}{} \\
\hline
\end{tabular}

Tabel 3. Hasil Output Uji Wilcoxon

\begin{tabular}{|c|c|c|c|c|c|c|c|c|c|}
\hline & & \multicolumn{5}{|c|}{ Paired Differences } & \multirow{3}{*}{ T } & \multirow{3}{*}{ Df } & \multirow{3}{*}{ Sig. (2-tailed } \\
\hline & & \multirow[t]{2}{*}{ Mean } & \multirow{2}{*}{$\begin{array}{c}\text { Std. } \\
\text { Deviation }\end{array}$} & \multirow{2}{*}{$\begin{array}{l}\text { Std. } \\
\text { Error } \\
\text { Mean }\end{array}$} & \multicolumn{2}{|c|}{$\begin{array}{c}95 \% \text { Confidence Interval } \\
\text { of the Difference }\end{array}$} & & & \\
\hline & & & & & Lower & Upper & & & \\
\hline Pair 1 & $\begin{array}{l}\text { Pre } \\
\text { Post }\end{array}$ & $-1.37353 \mathrm{E} 1$ & 2.88737 & .49518 & -14.74274 & -12.72784 & -27.738 & 33 & .000 \\
\hline
\end{tabular}

Kegiatan belajar dalam pembelajaran berorientasi CEP diarahkan pada experimental learning, yaitu mengadaptasi kehidupan yang dilakukan ke dalam kegiatan belajar yang didasarkan pada aktivitas nyata di laboratorium, diskusi dengan teman sejawat, yang kemudian dijadikan ide dan pengembangan konsep baru (Utomo et al., 2015). Misalnya pada saat praktikum pembuatan garam meja dari garam dapur yang dilakukan di laboratorium, kemudian diadakan diskusi kelas membahas hasil praktikum. Melalui pembelajaran ini siswa juga akan mendapatkan pengalaman langsung dalam menangani bahan kimia dan sumber lingkungan (Tukiran et al., 2017). Gagasan dan pandangan akan suatu fenomena maupun pertanyaan-pertanyaan 


\section{T. Wibowo \& Ariyatun}

yang muncul dari siswa merupakan hasil dari mengkontruksi pengetahuan dalam pikiran siswa (Keenan et al., 2001). Pengetahuan dikembangkan oleh siswa sendiri secara aktif karena pengetahuan yang diperoleh dari guru ke siswa harus dilakukan melalui proses.

Hal tersebut sesuai dengan prinsip-prinsip kontruktivisme, yaitu (1) pengetahuan dikembangkan oleh siswa sendiri, (2) pengetahuan tidak dapat ditransfer dari guru ke siswa, (3) siswa aktif mengkontruksi pengetahuan secara kontinu, sehingga terjadi perubahan konsep menuju ke konsep yang lebih jelas berdasarkan konsep ilmiah, dan (4) guru hanya menyediakan media supaya proses pengembangan siswa berjalan lancar (Utami dkk., 2009). Pada penelitian yang dilakukan ini, guru membantu proses konstruksi siswa adalah penerapan pembelajaran berorientasi CEP pada proses pembelajaran kimia.

Pada pembelajaran kimia berorientasi CEP, selain memperoleh ilmu pengetahuan, siswa juga memperoleh pengalaman praktis serta keterampilan dalam membuat suatu produk sehingga dapat membangkitkan semangat untuk berwirausaha (Rahmawanna dkk., 2016). Siswa begitu bersemangat untuk mencoba membuat produk-produk dengan memanfaatkan bahan-bahan yang tersedia di sekitar, misalkan dengan membuat telur asin. Materi pelajaran juga senantiasa dikaitkan dengan fenomena-fenomena yang dapat ditemui di sekitar siswa sehingga mereka lebih mudah menyerap materi yang diberikan, meskipun materi tersebut masih asing bagi siswa.

Penyampaian materi pelajaran yang dikaitkan dengan situasi nyata siswa dan penerapannya dalam kehidupan sehari-hari tersebut sesuai dengan model pembelajaran kontekstual dimana dalam proses pembelajarannya guru mengubungkan materi dengan lingkungan sekitar sehingga siswa dapat menghubungkan antara pengetahuan yang mereka dapatkan dengan menerapkannya dalam kehidupan sehari-hari. Hal tersebut telah mengubah pola pikir siswa yang semula menganggap materi kimia terlalu abstrak, sekarang sudah mulai terkikis karena mereka telah dapat menemukan sendiri hal-hal yang
Penerapan Pembelajaran Berorientasi

Chemoentrepreneurship (CEP) terhadap

Kreativitas Siswa SMA Modern Pondok

Selamat pada Materi Kelarutan dan $K_{s p}$ berkaitan dengan kimia yang ada di sekitar siswa. Selain itu pembelajaran yang mengimplementasikan CEP merupakan pembelajaran kontekstual yang memungkinkan siswa untuk dapat mempelajari proses produksi material menjadi produk berguna yang memiliki nilai ekonomi, sehingga kreativitas siswa mulai tergali dan mempunyai ketertarikan dalam mengikuti proses pembelajaran (Sumarti et al., 2014a).

Pembelajaran kimia dengan berorientasi $C E P$ sesuai dengan pembelajaran keterampilan proses yang proses pembelajarannya meliputi kegiatan melakukan observasi, menghitung, mengukur, mengklasifikasi, melakukan eksperimen, menafsirkan data, menerapkan konsep, menyimpulkan dan mengkomunikasikan. Melalui pembelajaran berorientasi CEP ini siswa diberi kesempatan untuk berlatih menggunakan keterampilanketerampilan proses tersebut. Seperti halnya pembelajaran keterampilan proses, pembelajaran kimia yang berorientasi CEP juga menekankan bagaimana siswa belajar dan mengelola pengetahuan yang diperolehnya, sehingga dipahami dan dapat digunakan sebagai bekal untuk memenuhi kebutuhannya dalam kehidupan di masyarakat.

Berdasarkan hasil penelitian yang telah dilakukan ini dapat diketahui bahwa pembelajaran kimia berorientasi CEP memiliki dampak positif terhadap kegiatan belajar mengajar, yaitu dapat meningkatkan kreativitas siswa.

Dengan demikian, diharapkan guru dapat menerapkan pembelajaran berorientasi CEP dalam proses pembelajaran kimia. Hanya saja, guru harus mengetahui secara pasti materi-materi kimia yang tepat dan sesuai dengan pembelajaran CEP, pembuatan desain pembelajarannya harus sesuai antara objek-objek atau fenomena-fenomena yang dipelajari dengan kegiatan siswa. 
T. Wibowo \& Ariyatun

\section{KESIMPULAN}

Berdasarkan hasil penelitian tersebut dapat disimpulkan bahwa pembelajaran kimia berorientasi CEP dapat meningkatkan kreativitas siswa dalam pembelajaran. Hal ini dibuktikan dengan peningkatan skor kreativitas siswa pada pre-test dengan rerata 27,8 menjadi 41,5 saat post-test. Hal lain juga ditunjukkan dengan hasil uji Wilcoxon diperoleh thitung sebesar $-27,738$ dan $t_{\text {tabel }}$ sebesar 2,034 (thitung $<t_{\text {tabel }}=-27,738<-2,034$ ) dan nilai $N$-gain diperoleh sebesar 0,62.
Penerapan Pembelajaran Berorientasi Chemoentrepreneurship (CEP) terhadap Kreativitas Siswa SMA Modern Pondok Selamat pada Materi Kelarutan dan $K_{s p}$ 


\section{DAFTAR PUSTAKA}

Alma, B. (2007). Kewirausahaan Untuk Mahasiswa Dan Umum. Bandung: Alfabeta

Creswell, John W.. (2013). Research Design: Qualitative, Quantitative, and Mixed Methods Approaches. California: SAGE Publications.

Damayanti, D. R., Catur, A. N., \& Yamtinah, S.. (2014). Upaya Peningkatan Kreativitas dan Prestasi Belajar Melalui Penerapan Model Pembelajaran Problem Solving Disertai Hierarki Konsep Pada Materi Hidrolisis Garam Siswa Kelas XI Semester Genap SMA Negeri 1 Ngemplak Tahun Pelajaran 2013/2014. Jurnal Pendidikan Kimia, $3(4)$.

Haryati, S. P. (2014). Peningkatan Kreativitas Berwirausaha Siswa Kelas XII Jasa Boga 1 dalam Pengolahan Limbah Bandeng Sebagai Peluang Usaha Melalui Unit Produksi di SMK Negeri 3 Pati. Jurnal Pendidikan IImu Sosial, 24(2).

Hendro. (2011). Dasar-Dasar Kewirausahaan. Jakarta: Erlangga

Keenan, C.W., Kleinfelter, D.C., \& Wood, J.H. (2001). Kimia Untuk Universitas Jilid I. Jakarta: PT. Erlangga.

Khan, G. N, \& Arshad, A. (2012). Higher Secondary School Students' Attitude towards Chemistry. Journal of Asian Social Science, 8(6), 165-169.

Kusuma, E., \& Siadi, K. (2010). Pengembangan Bahan Ajar Kimia Berorientasi Chemo-Entrepreneurship untuk Meningkatkan Hasil Belajar dan Life Skill Mahasiwa. Jurnal Inovasi Pendidikan Kimia, 4(1).

Lelono, W. T. (2015). Peningkatan Kemampuan Chemo-Entrepreneurship Siswa Melalui Penerapan Konsep
Koloid yang Berorientasi Life Skill. Jurnal Inovasi Pendidikan Kimia. 9(1), 1450-1458.

Mulyasa, E. (2004). Kurikulum Berbasis Kompetensi. Bandung : PT. Remaja Rosdakarya

Munandar, U. (2009). Mengembangkan Bakat dan Kreativitas Anak Sekolah. Jakarta: PT. Gramedia.

Mursiti, S., Wahyukaeni, T. \& Sudarmin. (2008). Pembelajaran Dengan Pendekatan Chemo-Entrepreneurship dan Penggunaan Game Simulation Sebagai Media Chemo-Edutainment Untuk Meningkatkan Hasil Belajar, Kreativitas, dan Life Skill. Jurnal Inovasi Pendidikan Kimia, 2(2), 274-280.

Nurmasari, N., Supartono \& Sedyawati, S. M.. (2015). Keefektifan Pembelajaran Berorientasi Chemoentrepreneurship Pada Pemahaman Konsep dan Kemampuan Life Skill Siswa. Jurnal Inovasi Pendidikan Kimia, 8(1), 12891299.

Paristiowatia, M., Slameta, R., \& Sebastiana, R.. (2015). Chemo-Entrepreneurship: Learning Approach for Improving Student's Cooperation and Communication (Case Study at Secondary School, Jakarta). INTE 2014; Procedia - Social and Behavioral Sciences (Elsevier), 174, 1723 - 1730.

Pratiwi, Y., Mulyani, S., \& Ashadi, A. (2015). Upaya Peningkatan Prestasi Belajar dan Interaksi Sosial Siswa Dengan Menggunakan Metode Pembelajaran Teams Games Tournament (TGT) dilengkapi Media Peta Konsep pada Materi Kelarutan dan Hasil Kali Kelarutan Siswa Kelas XI IPA SMA Batik 1 Surakarta. Jurnal Pendidikan Kimia, 4(1), 182-188.

Rahmawanna, R., Adlim, A., \& Halim, A. (2016). Pengaruh Penerapan Pendekatan Chemo-entrepreneurship (CEP) Terhadap Sikap Siswa pada 
T. Wibowo \& Ariyatun

Pelajaran Kimia dan Minat Berwirausaha. Jurnal Pendidikan Sains Indonesia, 4(2), 113-117.

Rasheed, H. S. (2005). Developing Entrepreneurial Characteristics in Youth: The Effects of Education and Enterprise Experience. International Journal of Entrepreneurship Education, 1(1), 1-19.

Rohmadi. (2012). Pendekatan CEP (Chemoentrepreneurship).

(http://www.rohmadi.info/web/read/pend ekatan-cep-chemo-entrepreneurship/), diakses 29 Juni 2018.

Rohmadi, M. (2011). Pembelajaran Dengan Pendekatan CEP (ChemoEntrepreneurship) yang Bervisi SETS (Sceince, Environment, Technology and Society) Guna Meningkatkan Kualitas Pembelajaran. Jurnal EducatiO, 6(1), 17-37.

Sudharson, K., Ali, A. M., \& Sermakani, A.M. (2013). An Organizational Perspective ofKnowledge Communication in Developing Entrepreneurship Education for Engineering Students. The 2nd International Conference on Information; Procedia - Social and Behavioral Sciences (Elsevier), 73, 590-597.

Sumarni, W. (2009). Peningkatan Efektivitas Perkuliahan Kimia Dasar Melalui Pembelajaran Berorientasi Chemoentrepreneurship (CEP) Menggunakan Media Chemoedutainment (CET). Lembaran IImu Kependidikan, 38(1).

Sumarti, S. S., Supartono \& Diniy, H. H. (2014a). Material Module Development of Colloid Orienting on LocalAdvantage-Based ChemoEntrepreneurship to Improve Students' Soft Skill. International Journal of Humanities and Management Sciences (IJHMS), 2(1). ISSN 2320-4044.
Penerapan Pembelajaran Berorientasi Chemoentrepreneurship (CEP) terhadap Kreativitas Siswa SMA Modern Pondok Selamat pada Materi Kelarutan dan $K_{s p}$

Sumarti, S. S., Supartono \& Noviyanti. (2014b). Learning Tools Development for Chemoentrepreneurship - Based Hydrocarbon and Petroleum in Increasing the Students' Soft Skills and Interest in Entrepreneurship. International Journal of Recent Advances in Multidisciplinary Research, 1(2), 4-9.

Supartono. (2006). Upaya Peningkatan Hasil Belajar Kreatifitas Siswa SMA Melalui Pembelajaran Kimia dengan Pendekatan Chemoentrepreneurship (CEP). Prosiding Seminar Nasional Kimia dan Pendidikan Kimia 2006. Jurusan Kimia FMIPA UNNES. ISBN: 9799957984x: 280-29.

Supartono., Nanik, W., \& Anita, H.S. (2009a). Kajian Prestasi Belajar Siswa SMA dengan Metode Student Teams Achievement Divisions melalui Pendekatan Chemo-Entrepreneurship. Jurnal Inovasi Pendidikan Kimia. 3(1): 337-344.

Supartono, Saptorini \& Asmorowati, D. S. (2009b). Pembelajaran Kimia Menggunakan Kolaborasi Konstruktif dan Inkuiri Berorientasi Chemoentrepreneurship. Jurnal Inovasi Pendidikan Kimia. 3(2): 476-483.

Surachman, E. (2011). Menumbuhkan Sikap Kewirausahaan: Surveu Tiga Faktor Pemdorong di Kecamatan Plered Purwakarta. Jurnal Sosialita, 9(1), ISSN: 1411-7134.

Tukiran, Suyatno \& Hidayati, N.. (2017). Developing Teaching Materials of Natural Product Chemistry to Increase Student's Life Skills. Journal of Turkish Science Education, 14(2), 27-41.

Utami, B., Iskandar, S. M., \& Ibnu, S.. (2009). Penerapan Pembelajaran Konstruktivisme dalam Pembelajaran Kimia di SMU. Prosiding Seminar Nasional Kimia dan Pendidikan Kimia. ISBN: 979-498-467-1.

Jurnal Tadris Kimiya 3, 1 (Juni 2018): 62-72 
T. Wibowo \& Ariyatun

Utomo, A. B., Widodo, J., Supartono \& Haryono. (2015) Hypothetical Model Of Training Management For Chemistry Teachers Of Senior High Schools In Semarang. International Journal of Education and Research. 3(7).
Penerapan Pembelajaran Berorientasi Chemoentrepreneurship (CEP) terhadap Kreativitas Siswa SMA Modern Pondok Selamat pada Materi Kelarutan dan $K_{s p}$ 